\title{
Primary Research of the Advantages and the Cost Control of the ABC \& EVA Integrated System
}

\author{
Haibo $\mathrm{Hu}$ \\ School of Economics and Management, University of South China, Hengyang 421001, China \\ Tel: 86-734-8282-147 E-mail: foxhaibo@163.com \\ A Project Supported by Scientific Research Fund of Hunan Provincial Education Department (08C719).
} Abstract

The integrated product of Activity-Based Costing (ABC) and Economic Value Added (EVA) is the ABC \& EVA system, i.e. the integrated cost system. Traditional ABC method gives priority to the interior activity chain of enterprise to implement the cost analysis, but ignores the capital cost, so the cost accounting is not complete. The ABC \& EVA system brings the capital cost into the cost management, which could not only open out the real economic value created by the cost objects, but extend the pure cost computation of $\mathrm{ABC}$ to the performance evaluation. Based on the principle of the ABC \& EVA system, the enterprise cost control strategies under the integrated cost system are proposed.

Keywords: Activity-Based Costing (ABC), Economic Value Added (EVA), Integrated cost system, Cost control

The occurrence of $\mathrm{ABC}$ was thought as a revolution of the cost accounting. Its special cost concept of "activities consume resources and products consume activities" could rectify failed product cost information in the traditional cost accounting, and largely enhance the serviceability of the decisions of cost information. However, in the drastic competitive environment at present, single $\mathrm{ABC}$ cost information has not made enterprise acquire and keep long-term competitive advantages and value creation ability. The research emphases of ABC are mainly centralized in the process producing indirect costs in the domains such as production and logistics, but it ignores the distribution process producing the indirect costs in other domains. Especially, when the enterprise evaluates the investment item or the profitability of the new product, it will find that the ABC method could not reflect the capital cost consumed by the investment item or the new product, and the enterprise can not control the investment risk. Therefore, it is necessary to combine ABC and EVA.

\section{Integration of $A B C$ and EVA}

EVA is the economic profit of operating profit after tax minus all capital costs (including debt cost and equity cost). And it is the surplus cost minus all costs, and it is the index to measure the performance of the enterprise, and it could measure the shareholder fortune created by the enterprise, and it is a new index to evaluate the performance of the enterprise. Its basic idea could be described as that investors will invest capitals when they predict that the investment return rate is very high, and if the future return rate is very low, they may more select other investment opportunities. Therefore, the enterprise must create values for its shareholders, and managers have to make the enterprise produce sufficient values to compensate the capital cost, and if the investment return rate is lower than the capital cost, the shareholder fortune will be destroyed.

To improve the decision serviceability of the cost information of $\mathrm{ABC}, \mathrm{ABC}$ should combine with EVA. To bring the principle of EVA into $\mathrm{ABC}$ will make the cost management and the performance evaluation system more perfect and complete, and rectify the situation that $\mathrm{ABC}$ ignores the capital cost and underestimate the product cost. The combination of ABC and EVA will produce the so-called "ABC \& EVA integrated system". The ABC module in the system emphasizes the management cost, and the EVA module emphasizes the capital cost, and the combination of both will compose a complete and effective management tool. And this tool could not only avoid the deficiencies of $\mathrm{ABC}$, but make shareholders and managers realize the structure distribution and distribution base of the interior economic additional values, and confirm their own direction. Comparing with traditional cost computation methods and $\mathrm{ABC}$, the product cost of the "ABC \& EVA integrated system" is the real "complete cost" which includes not only the management cost, but also the capital cost.

\section{Advantages of the $A B C \&$ EVA integrated system}

The integrated management mode of ABC \& EVA has the advantages of ABC and EVA, and the introduction of EVA could improve the deficiency that ABC could not completely reflect the capital cost, and it is very important for the management of the enterprise. Comparing with ABC or EVA, the advantages of the integrated mode include following aspects.

(1) The integrated system could distribute the cost and capitals into various activities and activity centers, and the production cost could completely reflect all costs. By introducing EVA in the cost accounting process, the integrated system could more completely reflect the cost information of product. 
(2) The cost information provided by the integrated system is really "complete cost" which includes not only the management cost, but the capital cost, and it is propitious to make enterprise managers realize that the capital is precious and limited resource, and they will more effectively and reasonably utilize capitals and stop or reduce the wastes of capitals.

(3) More exact information of product cost could offer better base for the pricing of products. The cost is an important factor for the enterprise to price the product, and generally speaking, the reduction of cost will reduce the price of product, and the integrated system of ABC \& EVA would have more sales and profits, and the cost decides the lower limit of the product. Exact cost information will help the enterprise to compute proper and reasonable product price, which will influence the competitive state and the market share of the product in the market.

(4) Through accounting the product cost by the integrated mode of ABC \& EVA, those products would bring values for the enterprise would be confirmed. For those products, the enterprise could implement the cost control into each activity and make the activity analysis taking the activity as the center according to the requirements of $\mathrm{ABC}$, and carry out the cost control based on the cost driver to more effectively and sustainably reduce the cost. For those products which could not bring values for the enterprise, the enterprise could pursue the value maximization by new product combination.

(5) The integrated mode could not only check and evaluate the activities like $\mathrm{ABC}$, and the cost driver analysis could open out various important factors influencing the performance, and the measurement and evaluation of the performance could measure and evaluate the execution effect of activity, and it could also be applied in the management to check the management of the enterprise, promote the management to more accord with shareholders' benefits and make the management plan more effectively by the change of EVA.

(6) The integrated mode could associate activities with capitals by the pertinence analysis of activities and capitals to compute the EVA of each activity, so the managers of the enterprise could more deeply understand how to create the EVA of enterprise, and how to implement relative decisions about EVA to the level that the bottom organizations could operate.

(7) It is the reasonable judgment standard to take EVA as the cost object, which could strengthen managers' sensitivity for the value creation. Under $\mathrm{ABC}$, the standard to judge the rationality of cost object is the profit, but the profit will not certainly create values, and it may even destroy value, and if the standard is EVA, it could guarantee the value creation of the management, and help the enterprise to realize the target of value maximization.

\section{The cost control based on the ABC \& EVA integrated cost system}

The cost in the view of integrated cost is the integrated cost management concept integrating EVA and $\mathrm{ABC}$, and to fulfill the strategic demand of cost control, the EVA needs to be introduced based on ABC to realize the target of the lowest week resource cost of product life. The enterprise cost control based on the integrated cost view is the concept of "complete cost", and it includes the management costs and the capital costs in various activities, and it could compensate the structured deficiency that traditional activity cost view could not reflect the using cost and the opportunity cost, so the product cost will be controlled more completely and truly. The cost control based on the integrated cost view is the whole-process cost control concept to completely extend the range of cost control, and the cost control includes the pre-event control, the on-event control, and the past-event control.

\subsection{Pre-event cost control in the view of integrated cost}

The pre-event cost control is mainly to utilize the integrated cost view to control the design cost of product. The product design is the first part in the interior activity chain of enterprise, and it will decide the subsequent activities to large extent. The product design will largely influence the product performance, materials, technical flow, costs, and even the whole value chain. According to the estimation, $60 \% \sim 80 \%$ of the costs in the lifecycle of product have been confirmed in the stage of product design. Therefore, the product design is the most important cost driver for the enterprise, and the cost is induced by the activity, and different product design plans need different activities, and various activities consume different costs. The cost control of product design based on the integrated cost view is to evaluate the value after analyzing the management cost and the capital cost consumed in various parts of the production activity, and it more accords with shareholders' beneficial target.

\subsection{On-event cost control in the view of integrated cost}

The on-event cost control is mainly to strengthen the control and management of stock cost, production cost, and sales cost of the product in the view of integrated cost. The capital cost control in the stock part is mainly to check and evaluate the capitals occupied by the stock and the repertory of materials, commodities, and low-value consumables in various stock parts such as purchasing activity, receiving activity, checking activity, and storing 
activity, and confirm the optimal economic stock batches to maximally save capitals and reduce the stock cost and the capital cost. The cost control in the product part means the continual improvement activities in the production activities such as production preparation, equipment serving, production and assembly, and quality control for reducing the cost. By eliminating useless and low-efficient activities, continually improving the value-added activities, and continually researching new production modes to reduce the costs of the product manufacturing engineer with existing design and function, the existing production activities could be improved, and the efficiency would be further enhanced, and the production cost of product would be reduced finally. The cost control in the production stage in the view of integrated cost includes all costs such as components, parts, sets, activity centers, products, and capitals, and it would seek the cost control approach, eliminate the valueless activities, and realize the target of value maximization by the analysis of cost difference between the target economic profit with the actual executed profit. The cost control in the sales process mainly means to control the capitals consuming in the order-form disposal, package, transportation, and loading and unloading in the sales process, such as the price of account sale product, the taxation minus price, sales charge, taxation, and charges of storage for the sales department. The capital cost control is mainly to make the sales promotion well, withdraw the payments for goods, reduce the repertory, increase the charge consciousness, try to reduce the sales charges and payouts, prevent forming new "chain debts", and accordingly achieve the target of reducing the capital occupation, and quickening the capital circulation and turnover.

\subsection{Post-event cost control in the view of integrated cost}

The post-event cost control in the view of integrated cost mainly means the cost difference analysis of various activity centers and the value-added evaluation. The cost difference is the balance between the actual cost and the target cost. The control target index of certain cost charge is basically confirmed by taking the "quantity standard" to multiply the "price standard". The "quantity standard" is the consumption and man-hour needed to produce unit product in existing production technical condition, which is confirmed by the consumption ration and the labor ration required by the technical design department. The "price standard" is confirmed by the price and salary in the market.

The value-added evaluation is the most important method of the activity cost control, and it includes two basic approaches. The first one is to confirm whether each activity is the value-added activity or the non-value-added activity. And the second one is to eliminate the non-value-added activities or reduce the scale to the minimum degree according to the confirmation result. The value-added activity here includes three meanings. The first one is the custom value, and those activities which could finally fulfill the demand of customers are the value-added activities. And the second one is shareholders' rewards or values, and those activities which possess not only customer values and shareholders' value are the value-added activities. And the third one is the business value, i.e. though some activities have not customer value and shareholders' value, but they are the conditions to realize the customer value and shareholders' value, and these activities also belong to the value-added activities.

To sum up, in the view of integrated cost, the cost control includes the management cost and the capital cost in various activities, and it is the "complete cost", and it could compensate the structured deficiency that traditional activity cost view could not reflect the using cost and the opportunity cost. As viewed from the control process, the cost control is to control the costs from various activities including the design, stock, production, and sales. Based on the integrated cost view, the integrated cost control could realize the integration of cost control, enterprise strategy, management, resource allocation, and performance management, and accordingly enhance the cost control ability and the cost competition advantage for the enterprise, and help the enterprise to more effectively use the cost information and performance data to implement the enterprise strategy and enhance the competitive force of the enterprise.

\section{References}

Cooper R, Slagmulder R. (1999). Integrated Activity-Based Costing and Economic Value Added. Engineering Management Journal. No.80(17). P.16-17.

Li, Qi. (2008). Study on the Economic Value-added Enterprise Value Management System. Research of Finance and Accounting. No.11. P.55-56.

Li, Yanxi \& Ma, Lin. (2004). Frame and Application of Activity-based Costing on the Basis of Economic Value-added. Journal of Dalian University of Technology (Social Sciences). No.1. P.21-22.

Robert S. Kaplan, Anthony A. Atkinson. (1998). Advanced Management Accounting (Third Edition). Prentice Hall. P.520-523.

Wang, Fangjun, Wan, Weiwu \& Wang, Pingxin. (2004). Integrated Cost Calculating Model: Integrating Activity-based Costing and Economic Value-added. Systems Engineering-Theory \& Practice. No.3. P.33-34. 